Original Article

\title{
SPECTROPHOTOMETRIC DETERMINATION OF PROPRANOLOL HYDROCHLORIDE AND METOPROLOL TARTRATE IN PHARMACEUTICAL DOSAGE FORMS, SPIKED WATER AND BIOLOGICAL FLUIDS
}

\section{K. SHARMA ${ }^{1}$, JASVIR SINGH ${ }^{2}$, PUSHAP RAJ ${ }^{1}$}

${ }^{1}$ Department of Chemistry, Himachal Pradesh University, Shimla, Himachal Pradesh 171005, ${ }^{2}$ Institute of Engineering and Technology, Bhaddal, Ropar, Punjab 140108

Email: pushap.hp@gmail.com

Received: 17 Nov 2017 Revised and Accepted: 21 Dec 2017

\section{ABSTRACT}

Objective: A new spectrophotometric method for the determination of propranolol hydrochloride (PRO) and metoprolol tartrate (MTP), beta blocker drugs, has been developed for their analysis in pharmaceutical dosage forms for the purpose of quality control and water samples for monitoring impact on environmental water quality of natural sources and in biological fluids for ascertaining their physiological performance.

Methods: The method is based on the derivatization of the amino function present in these drugs to the corresponding yellow copper (I) drug dithiocarbamate derivative through reaction with carbon disulphide, pyridine and copper (I) perchlorate in aqueous acetonitrile and measuring absorbance at $406 \mathrm{~nm}$ for propranolol and $400 \mathrm{~nm}$ for metoprolol. The different experimental parameters affecting the development and stability of the colour were carefully studied and optimized.

Results: The Beer's law is obeyed in the range of $1.0-40.0 \mu \mathrm{g} / \mathrm{ml}$ of each drug solution with a correlation coefficient 0.999 . The maximum relative standard deviations (RSDs) in the analysis of pure PRO and MTP were 1.01 and $1.52 \%$ respectively. The recoveries of the drugs from pharmaceutical formulations, spiked water samples and biological fluids were in the range $98.0-100.5 \%$ with RSDs in the range $0.23-1.94 \%$ indicating good accuracy and precision of the method.

Conclusion: The instantaneous development of colour and its stability, well-established stoichiometry of the reaction and above simplicity and rapidity of procedures are some special attributes of the proposed method.

Keywords: Propranolol hydrochloride, Metoprolol tartrate, Spectrophotometric method, Spiked water samples, Simulated biological fluids.

(C) 2018 The Authors. Published by Innovare Academic Sciences Pvt Ltd. This is an open access article under the CC BY license (http://creativecommons.org/licenses/by/4.0/) DOI: http://dx.doi.org/10.22159/ijpps.2018v10i2.23682

\section{INTRODUCTION}

Propranolol hydrochloride (PRO), 1-[isopropylamino-3-[1naphthyloxy]-2-propanol hydrochloride (fig. $1 \mathrm{~A}$ ), and metoprolol tartrate (MTP), 1-(isopropylamino)-3-[p-(2-methoxyethyl) phenoxy] -2-propanol tartrate (fig. 1 B), are $\beta$-blocker drugs commonly used to treat several diseases such as hypertension, myocardial infarction, arrhythmias, angina pectoris and hyperthyroidism [1-4]. These drugs are also sometimes used as a doping agent in sports, but because of their sedative effects these are now listed as forbidden drugs [5-6]. PRO became the best-selling drug for treatment of a wide range of cardiovascular diseases. The progress in $\beta$-blocker drug development led to the introduction of MTP because of its relative selectivity for cardiac $\beta 1$-receptors. The pharmaceutical industry has the responsibility of supplying drugs in the purest forms to satisfy the medical profession and public demand. In the same context in order to maintain uniform therapeutic standards with respect to both dosage form and quality, it is highly desirable that the quality of the various dosage forms of these drugs being marketed be ensured. The beneficial effects of a drug are maximized when the plasmatic concentration remains in its therapeutic range. Therapeutic drug monitoring is a clinical practice, carried out through the quantification of the drug and its main metabolites in physiological fluids at several times after the ingestion of the pharmaceutical formulation [7]. $\beta$-blockers have also been found in the water affecting its quality characteristics when people excrete them and simply flush out the outdated and unused drugs and are now considered as water pollutants [8-9].

Owing to the therapeutical, pharmacological and environmental relevance of PRO and MTP their rapid and accurate determination in commercial formulations, biological fluids and water samples is of great importance. Several methods have been reported for the

determination of these drugs which includes spectrophotometry [10-12], spectrofluorimetry [13-14], gas chromatography-mass spectrometry (GC-MS) [15-16], high-performance liquid chromatography (HPLC) [17-18], liquid chromatography-mass spectrometry (LC-MS) [19-21], chemiluminescence [22-23], capillary electrophoresis [24-25] and voltammetry [26-27]. Spectrophotometric methods because of their inherent simplicity and rapidity of the procedure and low cost of the techniques find favour in most laboratories of limited means and consequently these methods continue to flourish.<smiles>CC(C)NCC(O)COc1cccc2ccccc12</smiles>

A<smiles>COCCc1ccc(OCC(O)CNC(C)C)cc1</smiles>

B

Fig. 1: Chemical structure of (A) PRO and (B) MTP

In our efforts to develop a spectrophotometric method for the determination of listed drugs, the reaction of their secondary amino function with carbon disulphide and copper (I) perchlorate in 
aqueous acetonitrile media in the presence of pyridine to form an intense yellow coloured copper (I)-drug dithiocarbamate complex is investigated. The analysis is accomplished by measuring the intensity of the yellow colour at $406 \mathrm{~nm}$ for PRO and $400 \mathrm{~nm}$ for MTP by direct colorimetric or photometric titrimetric procedures. The latter procedure is rapid and precise as no calibration graph is required to be prepared, but the former is more sensitive. Optimizations of various experimental parameters, stoichiometry and proposed mechanism of colour reaction are also studied in developing the method for its application to the analysis of these drugs in pharmaceutical formulation, water samples and biological fluids. In the latter context simulated biological fluids (blood plasma, urine and phosphate buffer saline) artificially prepared were used.

\section{MATERIALS AND METHODS}

\section{Apparatus}

All the absorbance measurements have been carried out using Varian-Cary 100 Bio UV-Visible Spectrophotometer and Bosch and Lomb spectrophotometer (spectronic $20 \mathrm{D}+$ ) with one $\mathrm{cm}$ matched glass cells. Microwave oven, (Samsung make) was used for carrying out hydrolysis and other reactions. Sonicator (Ultrasonic cleaner UC1202D) and centrifuge (Sigma laborzentrifugen 3K-30) were used during the investigations.

\section{Reagents and solutions}

The analytical standards of high purity of PRO (99\%) and MTP (98 $\%)$ were procured from Sigma Aldrich, Bangalore, India. Double distilled water was used throughout. A stock standard solution of PRO and MTP was prepared by dissolving $10 \mathrm{mg}$ of pure drug compound in $100 \mathrm{ml}$ of double distilled water for obtaining a working concentration of $100 \mu \mathrm{g} / \mathrm{ml}$ drug solution. Copper (I) perchlorate and its standard solution $(0.001 \mathrm{~mol} / \mathrm{l})$ was prepared by dissolving more than the calculated amount in acetonitrile and standardized by titrating it against standard ammonium hexanitrocerate (IV) solution using ferroin as an indicator [28]. Carbon disulphide (Merck, AR), pyridine (Merck, GS) and ethyl acetate (Merck, AR) were used as received. Commercial chloroform was purified by allowing it to stand over anhydrous potassium carbonate (AR) overnight and then distilled. The fractional distilling at $55^{\circ} \mathrm{C}$ was collected.

\section{Simulated biological fluids}

The simulated blood plasma, urine and phosphate buffer saline used for the determination of PRO and MTP are prepared as proposed by Kokubo et al. [29], Miller et al. [30] and Singh et al. [31] respectively.

\section{Standard procedure}

Aliquots $(0.1-2.0 \mathrm{ml})$ of the standard drug solutions $(100 \mu \mathrm{g} / \mathrm{ml})$ of PRO and MTP were taken in $5 \mathrm{ml}$-measuring flasks and volume made to $2 \mathrm{ml}$ with water. Each solution was mixed with $1 \mathrm{ml}$ of pyridine and one drop $(\sim 50 \mu \mathrm{l})$ of carbon disulphide and the contents were kept in a microwave for $40 \mathrm{~s}$ for the completion of the reaction. Each solution was then mixed with copper (I) perchlorate $(1 \mathrm{ml}, 0.001$ $\mathrm{mol} / \mathrm{lin}$ acetonitrile) and volume made up to the mark with acetonitrile. The yellow colour which developed immediately was measured at $406 \mathrm{~nm}$ for propranolol and $400 \mathrm{~nm}$ for metoprolol against a reagent blank. Calibration graphs were constructed for each drug compound by plotting absorbance corresponding to different concentrations of the drug.

\section{Photometric titration procedure}

Aliquots of standard solutions $(0.0002 \mathrm{~mol} / \mathrm{l})$ of PRO and MTP in distilled water were taken in colourimetric tubes and the volume made to $2 \mathrm{ml}$ with water. Each solution, then mixed with $1 \mathrm{ml}$ of pyridine and 1 drop of carbon disulphide and kept in the microwave for $40 \mathrm{~s}$. Each solution was then titrated photometrically at room temperature $\left(\sim 24^{\circ} \mathrm{C}\right)$ with standard copper (I) perchlorate $(0.0002$ $\mathrm{mol} / \mathrm{l}$ ) by adding reagent in small instalments, stirring the solution magnetically (with a specially designed stirring disk) each time and measuring the absorbance at their respective wavelengths i.e. 406 $\mathrm{nm}$ for PRO and $400 \mathrm{~nm}$ for MTP against a reagent blank. Absorbance values were corrected to the initial volume of the solution by multiplying the absorbance readings by a factor $\mathrm{V}+\mathrm{v} / \mathrm{V}$, where $V$ is the initial volume and $v$ is the volume of standard copper (I) perchlorate added for a particular absorbance reading being measured. A plot of absorbance versus $\mathrm{ml}$ of titrant was then made and the best straight line drawn between the points taken well before and after the equivalence point. An inverted L-shaped titration curve was obtained in each case and the intersection of linear segments was taken as the end point.

\section{Procedure for the assay of PRO and MTP in pharmaceutical formulations}

The following pharmaceutical formulations of these drugs were purchased from local authorized dealers: Inderal-40 (Abbott Healthcare Pvt. Ltd. Himachal Pradesh, India) labelled to contain 40 mg of PRO, Ciplar-10 (Cipla Ltd. Sikkim, India) labelled to contain 50 mg of PRO per tablet and Metolar-50 and Metolar-25 (Cipla Ltd. Goa, India) labelled to contain respectively 50 and $25 \mathrm{mg}$ of MTP per tablet. A known number of tablets (20 tablets) of each drug formulation were weighed and crushed into powder. A stock solution was prepared by dissolving accurately weighed amount equivalent to $10 \mathrm{mg}$ of active ingredient in distilled water and sonicated for $10 \mathrm{~min}$. The solution was filtered and the residue was washed 2-3 times with distilled water. The filtrate and washings were diluted to $100 \mathrm{ml}$ with distilled water. Suitable aliquots of the drug extracts were taken for analysis as described above for pure drug compounds, both by colorimetric as well as photometric titration procedures.

\section{Procedure for the assay of PRO and MTP in spiked water samples}

Tap water $(10 \mathrm{ml})$ taken in different flasks were mixed with various aliquots of the standard solution $(100 \mu \mathrm{g} / \mathrm{ml})$ of each drug. Each solution was mixed with $1 \mathrm{ml}$ of pyridine and one drop $(\sim 50 \mu \mathrm{l})$ of carbon disulphide. The contents were kept in a microwave for $40 \mathrm{~s}$ for the completion of the reaction. Each solution was then mixed with copper (I) perchlorate $(1 \mathrm{ml}, 0.001 \mathrm{~mol} / \mathrm{l}$ in acetonitrile). The yellow coloured solution was equilibrated with $5 \mathrm{ml}$ of chloroform for $5 \mathrm{~min}$. The yellow chloroform layer was separated and dried by shaking with anhydrous sodium sulphate $(2 \mathrm{~g})$ and the absorbance of the resulting yellow colour was measured at $418 \mathrm{~nm}$ and $414 \mathrm{~nm}$ respectively for PRO and MTP. The calibration graphs were constructed by plotting absorbance against concentration of the drug in the usual way. The analysis of the drug is made by referring the observed absorbance values to calibration graph. PRO and MTP in the ranges $1.0-40.0 \mu \mathrm{g} / \mathrm{ml}$ can be determined by this procedure.

\section{Procedure for the assay of PRO and MTP in simulated body fluids}

Simulated biological fluids viz. blood plasma, urine and phosphate buffer saline $(5 \mathrm{ml})$ taken in different $30 \mathrm{ml}$ centrifuge tubes, were mixed with suitable aliquots of the standard $(100 \mu \mathrm{g} / \mathrm{ml})$ solution of each drug. Each solution was then mixed with $5 \mathrm{ml}$ of $0.5 \mathrm{~mol} / \mathrm{l}$ ammonium hydroxide solution and sonicated for $5 \mathrm{~min}$. After sonication, $5 \mathrm{ml}$ of ethyl acetate was added to each solution, shaken for $5 \mathrm{~min}$ and the contents were centrifuged for $10 \mathrm{~min}$ at $3000 \mathrm{rpm}$. The supernatant (ethyl acetate layer) was separated and the solvent was evaporated to dryness over a water bath. The residue was dissolved in $2 \mathrm{ml}$ of distilled water and sonicated for $5 \mathrm{~min}$ and processed for analysis in the same manner as described above under standard procedure.

\section{RESULTS AND DISCUSSION}

\section{Spectral characterization}

Based on the reaction of primary and secondary amines with carbon disulphide in the presence of a base to form dithiocarbamate complexes, spectrophotometric methods for the determination of amines and carbon disulphide have been developed in our laboratory [32-34]. The advantage of this approach has now been demonstrated in the present work in the analysis of PRO and MTP drugs. The instantaneous development of colour, well-established stoichiometry of the colour reaction, the stability of colour and reagent solutions are some of the salient features of the proposed method. It possesses advantages over the existing spectro- 
photometric methods in terms of simplicity and rapidity of the procedures and sensitivity of the method (table 1 ).

In the proposed method the amino function of each drug is transformed into corresponding copper (I) drug dithiocarbamate complexes through reaction with carbon disulphide, copper (I) perchlorate in the presence of pyridine. The colour is measured at 406 and $400 \mathrm{~nm}$ respectively. The absorption spectra of copper (I) drug dithiocarbamates are shown in fig. 2. The plausible reaction mechanism is depicted in fig. 3.

Table 1: Comparison of the proposed method with the existing spectrophotometric methods for the determination of PRO and MTP

\begin{tabular}{|c|c|c|c|c|}
\hline \multirow[t]{2}{*}{ Reagents } & \multicolumn{2}{|c|}{ Linearity range $(\mu \mathrm{g} / \mathrm{ml})$} & \multirow[t]{2}{*}{ Reaction time } & \multirow[t]{2}{*}{ Reference } \\
\hline & PRO & MTP & & \\
\hline Iodine & $6-36$ & $6-36$ & $5 \mathrm{~min}$ & [8] \\
\hline Chloranil & $4-24$ & $4-24$ & $5 \mathrm{~min}$ & [8] \\
\hline Bromanil & $20-120$ & $20-120$ & $20 \mathrm{~min}$ & [8] \\
\hline 4-chloro-7-nitro-2,1,3-benzoxadiazole & -- & $0.8-60$ & $10 \mathrm{~min}$ & [9] \\
\hline 1-chloro-2,4-dinitrobenzene & $4-16$ & -- & $30 \min$ & [10] \\
\hline Carbon disulphide-pyridine-Copper(I) perchlorate & $1-40$ & $1-40$ & $40 \mathrm{~s}$ & Proposed method \\
\hline
\end{tabular}

PRO: propranolol hydrochloride, MTP: metoprolol tartrate.

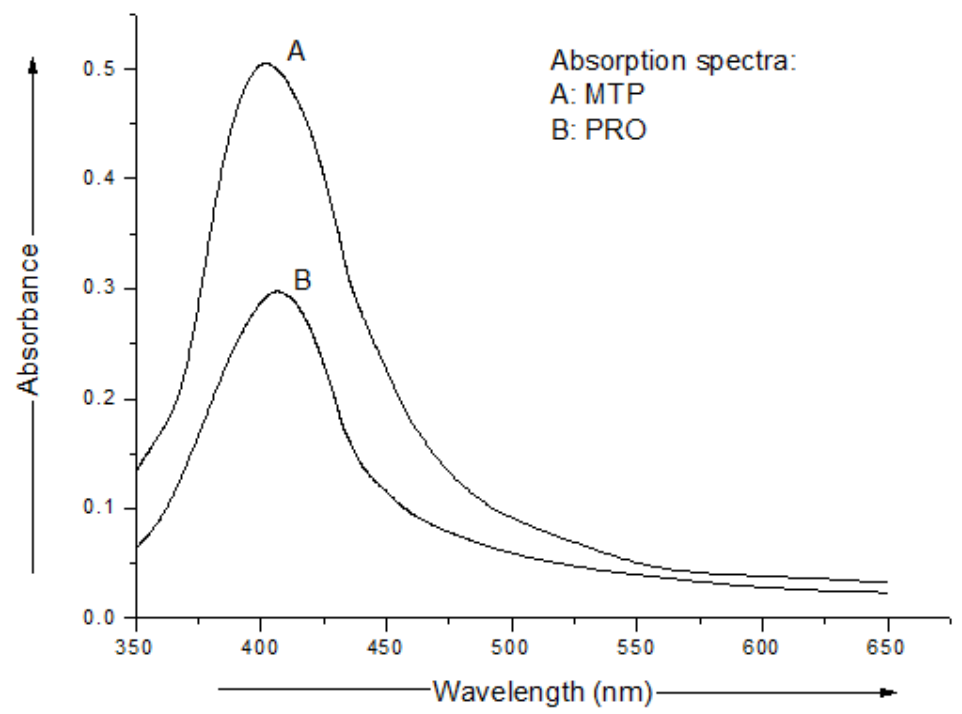

Fig. 2: Absorption spectra of PRO and MTP as copper (I) drug dithiocarbamate complex
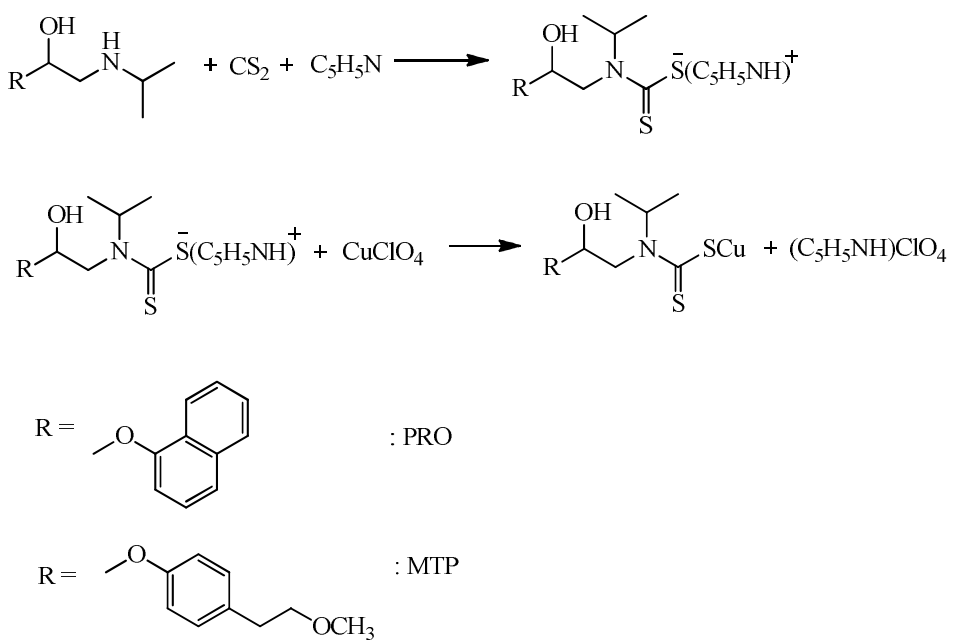

Fig. 3: Plausible reaction mechanism for the proposed method

During the course of the investigation, it was observed that the development of colour and its stability was less; colour intensity attained stable values after $15 \mathrm{~min}$. To overcome these problems the colour reactions forming the basis of proposed methods were carried out in a microwave oven. The microwave assisted reactions to accelerate the reaction rate and is an effective alternative to the conventional procedure as there is no loss of analyte and the contamination of atmosphere [35]. 


\section{Optimization of reaction conditions}

The various reaction conditions of PRO and MTP in pure and pharmaceutical formulations assay were carefully studied and optimised. The parameters optimized include heating time, the effect of reagent volume, the effect of extracting solvents and stability of colour.

\section{Effect of heating time}

The heating time in a microwave was varied from $10-80 \mathrm{~s}$ to obtain maximum colour intensity and stability. The best results were obtained corresponding to $40 \mathrm{~s}$ of heating (fig. 4). Reaction time less than $40 \mathrm{~s}$ gave less colour intensity.

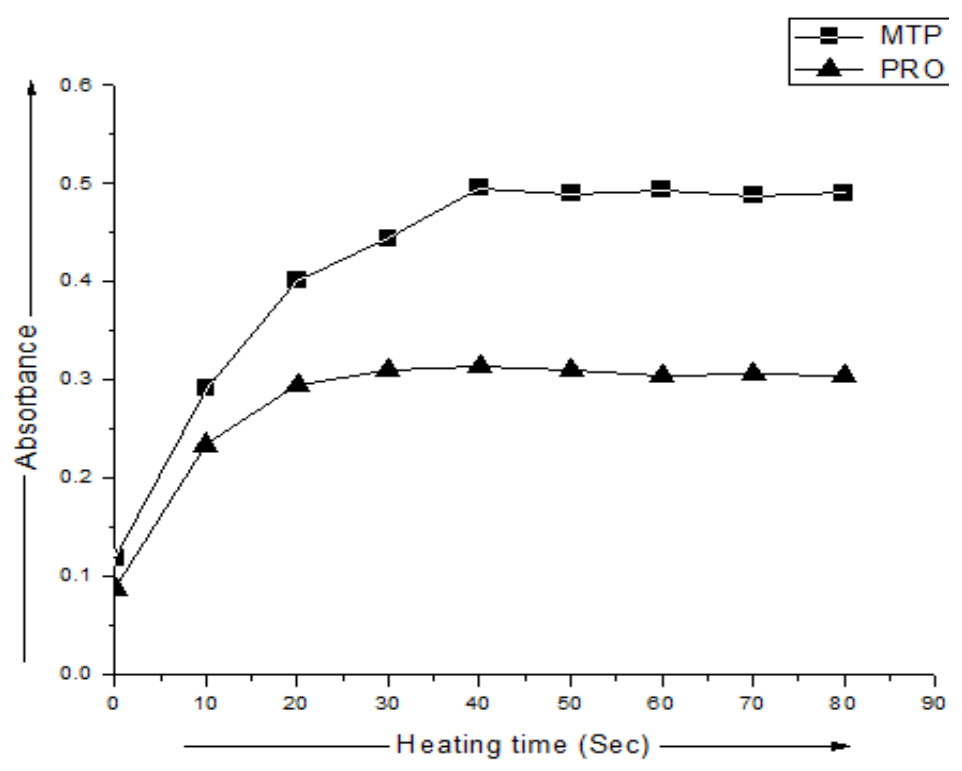

Fig. 4: Effect of heating time

\section{Effect of reagent volume and solvent}

The various volumes of a particular concentration of carbon disulphide, pyridine and copper (I) perchlorate were studied at a fixed concentration of the drug and their effects on the colour development and its intensity was investigated. It was found that the reproducible results with highest colour intensity were obtained with 1 drop $(\sim 50 \mu \mathrm{l})$ of carbon disulphide, $1 \mathrm{ml}$ of pyridine and $1 \mathrm{ml}$ of $0.001 \mathrm{~mol} / \mathrm{l}$ copper (I) perchlorate. The excess addition of reagents causes a decrease in the colour intensity.

\section{Effect of extracting solvents}

Of the three extracting solvents viz. chloroform, methyl isobutyl ketone (MIBK) and ethyl acetate for the extraction of the yellow copper (I) drug dithiocarbamate complex in the analysis of drugs from spiked water samples, chloroform has been selected because it extracts the complex almost completely and the extract show highest colour intensity and stability.

With regards to the assay of these drugs from simulated biological fluids, ethyl acetate has been found excellent giving higher recoveries of drugs.

\section{Stoichiometric ratio}

The stoichiometry of drug as its dithiocarbamate derivative and copper (I) reaction has been established by photometric titrations which in fact is the Job's method of continuous variation. In photometric titrations of each drug (as respective dithiocarbamate derivative) against copper (I) perchlorate at respective wavelengths, absorbance increases till 1:1 (1:2 for MTP) drug-copper reagent molar ratio indicating the formation of yellow copper (I) drug dithiocarbamate complex and thereafter it attains constant values thus establishing the above stoichiometry (fig. 5 and 6).

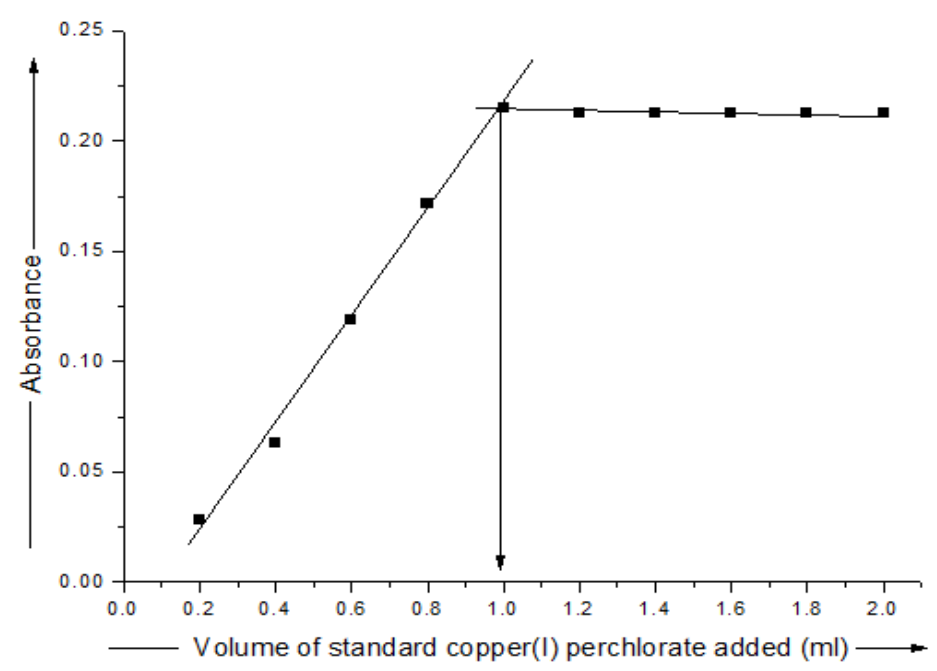

Fig. 5: Photometric titration curve of PRO with copper (I) perchlorate 


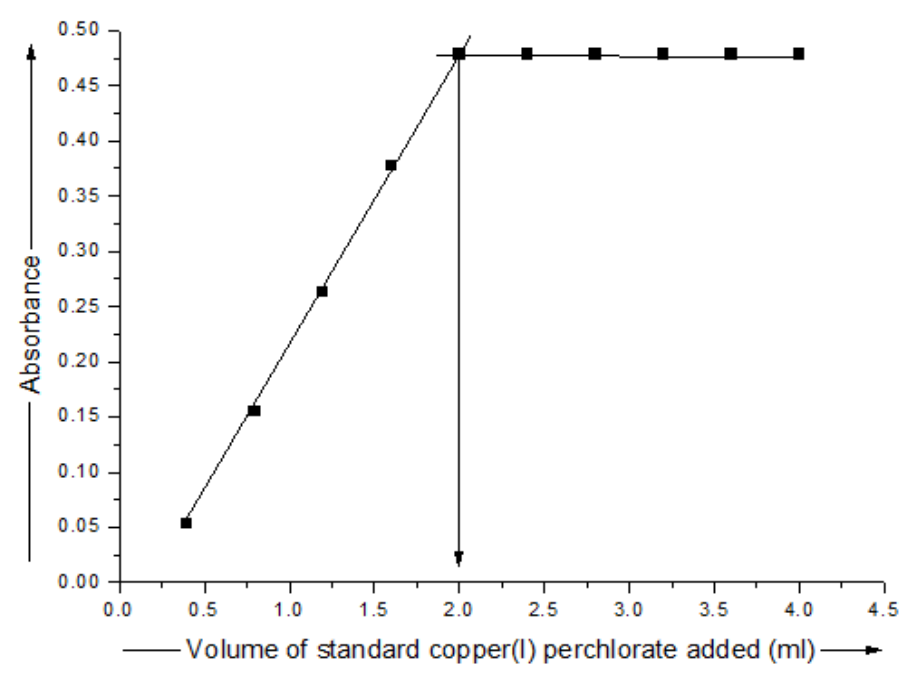

Fig. 6: Photometric titration curve of MTP with copper (I) perchlorate

\section{Validation of proposed method}

The following validation parameters were tested according to the guidelines set by the international conference on harmonization (ICH) [36]: linearity, accuracy, precision, limit of detection (LOD) and the limit of quantitation (LOQ).

\section{Linearity}

Under the optimized conditions, the linearity between absorbance and concentration (calibration graph) were in the range $1.0-40.0 \mu \mathrm{g} \mathrm{ml}$ for each drug compound (fig. 7). The linearity of calibration graphs was proved by the high values of the correlation coefficient (r) and the small values of the $y$-intercepts of the regression equations.

$$
\mathrm{Y}=\mathrm{mX}+\mathrm{C}
$$

(Where $\mathrm{Y}=$ Absorbance, $\mathrm{m}=$ slope $\mathrm{C}=$ intercept and $\mathrm{X}=$ concentration in $\mu \mathrm{g} / \mathrm{ml})$.

The various optical and calibration parameters viz. Beer's law range, Sandell's sensitivity, molar absorptivity, slope and intercept values for each drug compound have been calculated and are summarized in table 2.

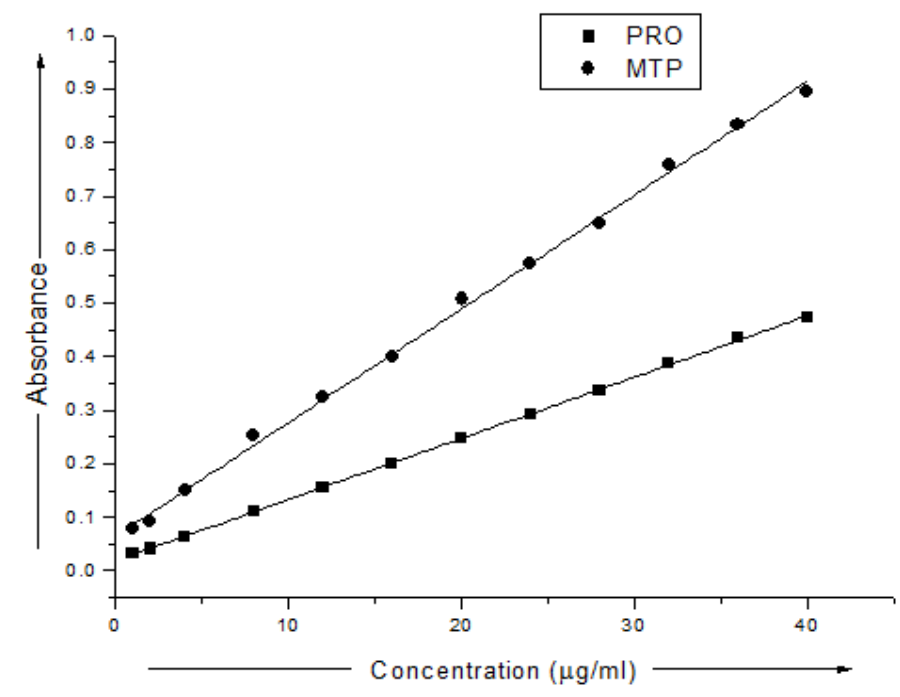

Fig. 7: Calibration graph of PRO and MTP as copper (I) drug dithiocarbamate complex

Table 2: Optical characteristics and statistical data of the regression line

\begin{tabular}{lll}
\hline Characteristics & PRO & MTP \\
\hline$\lambda_{\max }(\mathrm{nm})$ & 406 & 400 \\
Beer's law range $(\mu \mathrm{g} / \mathrm{ml})$ & $1.00-40.00$ & $1.00-40.00$ \\
Molar absorptivity $\left(\varepsilon, 1 \mathrm{~mol}^{-1} \mathrm{~cm}^{-1}\right)$ & $3.668 \times 10^{3}$ & $1.736 \times 10^{4}$ \\
Stability (min.) & 60 & 60 \\
Slope & 0.0114 & 0.0211 \\
Intercept & 0.0185 & 0.0626 \\
Correlation coefficient $(\mathrm{r})$ & 0.999 & 0.999 \\
Sandell's sensitivity $\left(\mu \mathrm{g} / \mathrm{cm}^{2}\right)$ & $8.06 \times 10^{-2}$ & $3.94 \times 10^{-2}$ \\
Limit of detection $(\mu \mathrm{g} / \mathrm{ml})$ & 0.28 & 0.18 \\
Limit of quantification $(\mu \mathrm{g} / \mathrm{ml})$ & 0.87 & 0.56 \\
\hline
\end{tabular}

PRO: propranolol hydrochloride, MTP: metoprolol tartrate. 


\section{Limit of detection and quantification}

The limits of detection (LOD) and quantification (LOQ) have been determined by ICH guidelines [36] using the following equation and also listed in table 2 .

$$
\begin{gathered}
\mathrm{LOD}=3.3 \sigma / \mathrm{s} \\
\text { And } \\
\mathrm{LOQ}=10 \mathrm{\sigma} / \mathrm{s}
\end{gathered}
$$

Where $\sigma$ is the standard deviation of the intercept of the regression line and $\mathrm{s}$ is the slope of the calibration curve.

\section{Accuracy and precision}

The accuracy and precision of the proposed method were evaluated by performing five replicate analyses of pure drug solutions at five different concentration levels over the ranges $2.0-40.0 \mu \mathrm{g} / \mathrm{ml}$ with a maximum relative standard deviation (RSD) of 1.01 and $1.52 \%$ respectively for PRO and MTP (table 3). Though photometric titrations of each drug compound as dithiocarbamate derivative with copper (I) perchlorate helped us in establishing the stoichiometry of the colour reaction, but have also afforded another method for the analysis of these drugs. PRO and MTP in the ranges $2.4-21.3 \mu \mathrm{g} / \mathrm{ml}$ and $2.7-24.6 \mu \mathrm{g} / \mathrm{ml}$ have been determined by a photometric titration method with maximum RSDs of 0.84 and 0.80 $\%$ (table 4). The results obtained with both the procedures, i.e. colourimetric as well as photometric titrimetric were in good agreement with those obtained using the comparison method [11]. The low values of the relative standard deviation $(<2.0 \%)$ in all cases show the good precision of the proposed method. The accuracy and reliability of the proposed assay are confirmed by applying the Student's t-test.

Table 3: Application of the proposed method to the determination of studied drugs in pure forms: standard procedure

\begin{tabular}{lllll}
\hline Drugs & Amount taken $(\boldsymbol{\mu g} / \mathbf{m l})$ & Amount found $\mathbf{a} \pm \mathbf{S D}(\boldsymbol{\mu g} / \mathbf{m l})$ & RE $(\%)$ & RSD $(\%)$ \\
\hline PRO & 2.0 & $2.01 \pm 0.02$ & 0.50 & 0.99 \\
& 10.0 & $9.94 \pm 0.10$ & 0.60 & 1.01 \\
& 20.0 & $19.88 \pm 0.16$ & 0.60 & 0.80 \\
MTP & 30.0 & $30.06 \pm 0.14$ & 0.20 & 0.46 \\
& 40.0 & $39.94 \pm 0.19$ & 0.15 & 0.48 \\
& 2.0 & $1.98 \pm 0.03$ & 1.00 & 1.52 \\
& 10.0 & $9.92 \pm 0.08$ & 0.80 & 0.80 \\
& 20.0 & $19.86 \pm 0.21$ & 0.70 & 0.81 \\
& 30.0 & $29.88 \pm 0.18$ & 0.40 & 0.60 \\
\end{tabular}

SD: standard deviation, RE: relative error, RSD: relative standard deviation, PRO: propranolol hydrochloride and MTP: metoprolol tartrate, aValues expressed as mean $\pm \mathrm{SD}(\mathrm{n}=5)$.

Table 4: Application of the proposed method to the determination of studied drugs in pure forms: photometric titration procedure

\begin{tabular}{lllll}
\hline Drugs & Amount taken $(\boldsymbol{\mu g} / \mathbf{m l})$ & Amount found $\mathbf{a} \mathbf{S D}(\boldsymbol{\mu g} / \mathbf{m l})$ & RE $(\%)$ & RSD $(\%)$ \\
\hline PRO & 2.4 & $2.38 \pm 0.02$ & 0.83 & 0.84 \\
& 7.1 & $7.08 \pm 0.05$ & 0.28 & 0.71 \\
& 11.8 & $11.73 \pm 0.09$ & 0.59 & 0.77 \\
MTP & 16.6 & $16.62 \pm 0.07$ & 0.12 & 0.42 \\
& 21.3 & $21.18 \pm 0.14$ & 0.56 & 0.66 \\
& 2.7 & $2.71 \pm 0.02$ & 0.37 & 0.74 \\
& 8.2 & $8.16 \pm 0.06$ & 0.49 & 0.73 \\
& 13.7 & $13.74 \pm 0.11$ & 0.29 & 0.80 \\
& 19.2 & $18.98 \pm 0.14$ & 0.63 & 0.74 \\
\end{tabular}

SD: standard deviation, RE: relative error, RSD: relative standard deviation, PRO: propranolol hydrochloride and MTP: metoprolol tartrate, aValues expressed as mean $\pm \mathrm{SD}(\mathrm{n}=5)$

\section{Interference}

Under the optimized experimental conditions, common excipients such as starch, talc, magnesium stearate and lactose did not interfere in the proposed method. The high percent recoveries of the active ingredients from commercial drug formulations further support the above observation (table 5 and 6 ).

\section{Assay of pharmaceutical formulations}

The results have been compared with an independent method [11]. The results of the determination of PRO and MTP from commercial pharmaceutical formulations are in good accordance with maker's

\begin{tabular}{|c|c|c|c|c|c|c|c|c|c|c|c|}
\hline \multirow{2}{*}{$\begin{array}{l}\text { Drug } \\
\text { formulations }\end{array}$} & \multirow{2}{*}{$\begin{array}{l}\text { Maker's } \\
\text { specificationa }\end{array}$} & \multicolumn{5}{|c|}{ Direct colourimetric procedure } & \multicolumn{5}{|c|}{ Photometric titration procedure } \\
\hline & & $\begin{array}{l}\text { Amount } \\
\text { taken } \\
(\mu \mathrm{g})\end{array}$ & $\begin{array}{l}\text { Amount } \\
\text { found } \pm S D \\
(\mu g)\end{array}$ & $\begin{array}{l}\text { Recovery } \\
(\%)\end{array}$ & $\begin{array}{l}\text { RSD } \\
(\%)\end{array}$ & $\begin{array}{l}\text { t- } \\
\text { value }^{c}\end{array}$ & $\begin{array}{l}\text { Amount } \\
\text { taken } \\
(\mu \mathrm{g})\end{array}$ & $\begin{array}{l}\text { Amount } \\
\text { found } \pm \text { SDD } \\
(\mu g)\end{array}$ & $\begin{array}{l}\text { Recovery } \\
(\%)\end{array}$ & $\begin{array}{l}\text { RSD } \\
(\%)\end{array}$ & $\begin{array}{l}\text { t- } \\
\text { value }\end{array}$ \\
\hline \multirow[t]{4}{*}{ Inderal-40 } & $40 \mathrm{mg}$ per & 4.0 & $3.97 \pm 0.05$ & 99.25 & 1.26 & 1.34 & 4.7 & $4.70 \pm 0.04$ & 99.37 & 0.85 & 1.68 \\
\hline & tablet & 8.0 & $7.92 \pm 0.13$ & 99.00 & 1.64 & 1.38 & 9.5 & $9.38 \pm 0.09$ & 99.15 & 0.96 & 1.99 \\
\hline & & 16.0 & $15.85 \pm 0.19$ & 99.06 & 1.19 & 1.76 & 14.2 & $14.25 \pm 0.13$ & 100.35 & 0.91 & 0.86 \\
\hline & & 32.0 & $32.13 \pm 0.21$ & 100.41 & 0.65 & 1.38 & 18.9 & $18.87 \pm 0.07$ & 99.68 & 0.37 & 1.92 \\
\hline \multirow[t]{4}{*}{ Ciplar-10 } & $10 \mathrm{mg}$ per & 4.0 & $3.95 \pm 0.06$ & 98.75 & 1.52 & 1.86 & 4.7 & $4.69 \pm 0.04$ & 99.15 & 0.85 & 2.24 \\
\hline & tablet & 8.0 & $8.06 \pm 0.15$ & 100.75 & 1.86 & 0.89 & 9.5 & $9.48 \pm 0.08$ & 100.21 & 0.84 & 0.56 \\
\hline & & 16.0 & $15.88 \pm 0.14$ & 99.25 & 0.88 & 1.92 & 14.2 & $14.09 \pm 0.14$ & 99.22 & 0.99 & 1.76 \\
\hline & & 32.0 & $31.92 \pm 0.20$ & 99.75 & 0.63 & 0.89 & 18.9 & $18.87 \pm 0.07$ & 99.68 & 0.37 & 1.92 \\
\hline
\end{tabular}
specification.

Table 5: Application of the proposed method to the determination of PRO in pharmaceutical formulations

SD: standard deviation, RSD: relative standard deviation, aMaker's specifications established by an independent method [11], bValues expressed as mean \pm SD $(n=5)$, cTheoretical t-value at $95 \%$ confidence level is 2.776 
Table 6: Application of the proposed method to the determination of MTP in pharmaceutical formulations

\begin{tabular}{|c|c|c|c|c|c|c|c|c|c|c|c|}
\hline \multirow{2}{*}{$\begin{array}{l}\text { Drug } \\
\text { Formulations }\end{array}$} & \multirow{2}{*}{$\begin{array}{l}\text { Maker's } \\
\text { specification }^{\text {a }}\end{array}$} & \multicolumn{5}{|c|}{ Direct colorimetric procedure } & \multicolumn{5}{|c|}{ Photometric titration procedure } \\
\hline & & $\begin{array}{l}\text { Amount } \\
\text { taken } \\
(\mu \mathrm{g})\end{array}$ & $\begin{array}{l}\text { Amount } \\
\text { found }^{b} \pm S D \\
(\mu g)\end{array}$ & $\begin{array}{l}\text { Recovery } \\
(\%)\end{array}$ & $\begin{array}{l}\text { RSD } \\
\text { (\%) }\end{array}$ & $\begin{array}{l}\text { t- } \\
\text { value }\end{array}$ & $\begin{array}{l}\text { Amount } \\
\text { taken } \\
(\mu \mathrm{g})\end{array}$ & $\begin{array}{l}\text { Amount } \\
\text { found }^{b} \pm S D \\
(\mu g)\end{array}$ & $\begin{array}{l}\text { Recovery } \\
(\%)\end{array}$ & $\begin{array}{l}\text { RSD } \\
(\%)\end{array}$ & $\begin{array}{l}\text { t- } \\
\text { value }^{c}\end{array}$ \\
\hline \multirow[t]{4}{*}{ Metolar-50 } & $50 \mathrm{mg}$ per & 4.0 & $4.02 \pm 0.07$ & 100.50 & 1.74 & 0.64 & 5.5 & $5.49 \pm 0.03$ & 99.82 & 0.55 & 0.74 \\
\hline & tablet & 8.0 & $7.89 \pm 0.15$ & 98.62 & 1.90 & 1.64 & 11 & $10.90 \pm 0.10$ & 99.09 & 0.92 & 1.96 \\
\hline & & 16.0 & $16.07 \pm 0.09$ & 100.44 & 0.56 & 1.74 & 16.4 & $16.32 \pm 0.16$ & 99.51 & 0.98 & 1.67 \\
\hline & & 32.0 & $32.04 \pm 0.19$ & 100.12 & 0.59 & 0.47 & 21.9 & $21.78 \pm 0.18$ & 99.45 & 0.83 & 1.61 \\
\hline \multirow[t]{4}{*}{ Metolar-25 } & $25 \mathrm{mg}$ per & 4.0 & $3.98 \pm 0.03$ & 99.50 & 0.75 & 1.49 & 5.5 & $5.52 \pm 0.03$ & 100.36 & 0.54 & 2.23 \\
\hline & tablet & 8.0 & $8.03 \pm 0.12$ & 100.37 & 1.49 & 0.56 & 11 & $10.93 \pm 0.10$ & 99.36 & 0.91 & 2.01 \\
\hline & & 16.0 & $15.93 \pm 0.17$ & 99.56 & 1.07 & 0.92 & 16.4 & $16.28 \pm 0.15$ & 99.27 & 0.92 & 2.38 \\
\hline & & 32.0 & $31.90 \pm 0.20$ & 99.69 & 0.63 & 1.12 & 21.9 & $21.76 \pm 0.19$ & 99.36 & 0.87 & 1.76 \\
\hline
\end{tabular}

SD: standard deviation, RSD: relative standard deviation, aMaker's specifications established by an independent method [11], bValues expressed as mean \pm SD $(n=5)$, cTheoretical $t$-value at $95 \%$ confidence level is 2.776

Table 7: Application of the proposed method to the determination of PRO and MTP in spiked water samples

\begin{tabular}{llll}
\hline Drug & Amount taken $(\boldsymbol{\mu g})$ & Amount found $\boldsymbol{~} \boldsymbol{\mu g})$ & Recovery (\%) \\
\hline PRO & 10.0 & $9.95 \pm 0.08$ & 99.50 \\
& 20.0 & $19.89 \pm 0.13$ & 99.45 \\
MTP & 30.0 & $29.76 \pm 0.24$ & 99.20 \\
& 10.0 & $9.97 \pm 0.07$ & 9.65 \\
& 20.0 & $19.83 \pm 0.17$ & 0.81 \\
\\
\hline
\end{tabular}

RSD: relative standard deviation, PRO: propranolol hydrochloride and MTP: metoprolol tartrate, aValues expressed as mean \pm SD $(n=5)$

Table 8: Application of the proposed method to the determination of PRO and MTP in simulated blood plasma

\begin{tabular}{llll}
\hline Drug & Amount taken $(\boldsymbol{\mu g})$ & Amount found $^{\mathbf{a}} \boldsymbol{( \mu \mathrm { g } )}$ & Recovery (\%) \\
\hline PRO & 10.0 & $9.80 \pm 0.19$ & 98.00 \\
& 20.0 & $19.84 \pm 0.17$ & 99.20 \\
MTP & 30.0 & $29.75 \pm 0.25$ & 99.17 \\
& 10.0 & $9.92 \pm 0.09$ & 0.86 \\
& 20.0 & $19.93 \pm 0.12$ & 99.20 \\
\\
\hline
\end{tabular}

RSD: relative standard deviation, PRO: propranolol hydrochloride and MTP: metoprolol tartrate, aValues expressed as mean \pm SD $(n=5)$.

Table 9: Application of the proposed method to the determination of PRO and MTP in simulated urine

\begin{tabular}{|c|c|c|c|c|}
\hline Drug & Amount taken $(\mu \mathrm{g})$ & Amount found ${ }^{\mathrm{a}}(\mu \mathrm{g})$ & Recovery (\%) & RSD (\%) \\
\hline \multirow[t]{3}{*}{ PRO } & 10.0 & $9.97 \pm 0.09$ & 99.70 & 0.90 \\
\hline & 20.0 & $19.91 \pm 0.18$ & 99.55 & 0.90 \\
\hline & 30.0 & $30.04 \pm 0.07$ & 100.13 & 0.23 \\
\hline \multirow[t]{3}{*}{ MTP } & 10.0 & $9.92 \pm 0.11$ & 99.20 & 1.11 \\
\hline & 20.0 & $19.88 \pm 0.19$ & 99.40 & 0.96 \\
\hline & 30.0 & $29.91 \pm 0.23$ & 99.70 & 0.77 \\
\hline
\end{tabular}

RSD: relative standard deviation, PRO: propranolol hydrochloride and MTP: metoprolol tartrate, aValues expressed as mean \pm SD ( $\mathrm{n}=5$ ).

Table 10: Application of the proposed method to the determination of PRO and MTP in phosphate buffer saline

\begin{tabular}{|c|c|c|c|c|}
\hline Drug & Amount taken $(\mu \mathrm{g})$ & Amount found ${ }^{a}(\mu g)$ & Recovery (\%) & RSD (\%) \\
\hline \multirow[t]{3}{*}{ PRO } & 10.0 & $9.90 \pm 0.18$ & 99.00 & 1.82 \\
\hline & 20.0 & $19.88 \pm 0.21$ & 99.40 & 1.06 \\
\hline & 30.0 & $30.04 \pm 0.24$ & 100.13 & 0.80 \\
\hline \multirow[t]{3}{*}{ MTP } & 10.0 & $9.95 \pm 0.07$ & 99.50 & 0.70 \\
\hline & 20.0 & $19.76 \pm 0.24$ & 98.80 & 1.21 \\
\hline & 30.0 & $29.84 \pm 0.19$ & 99.47 & 0.64 \\
\hline
\end{tabular}

RSD: relative standard deviation, PRO: propranolol hydrochloride and MTP: metoprolol tartrate, aValues expressed as mean \pm SD ( $\mathrm{n}=5$ ).

\section{Recovery from spiked water samples}

The method when applied to the assay of each drug compound from spiked water samples gave high recoveries and low RSDs values indicating good accuracy and precision of the method (table 7).
Recovery from simulated biological fluids

The method has also been successfully validated for the determination of PRO and MTP in simulated biological fluids viz. simulated blood plasma, simulated urine and phosphate buffer 
saline. The recoveries were good, in the range $98.00-100.13 \%$ with RSDs in the ranges $0.23-1.94 \%$. (table 8-10).

\section{CONCLUSION}

The proposed spectrophotometric method is simple, rapid and sensitive offering analysis of PRO and MTP drugs both by colorimetric as well as photometric titration procedures. The latter also supports the stoichiometries of the colour reactions forming the basis of proposed methods. The instantaneous development of colour and its stability and well established stoichiometry of the reaction are other salient of the methods. The high recoveries of drugs from their commercial pharmaceutical formulations, spiked water samples and simulated biological fluids indicate good accuracy and precision of the method and hence can be recommended for their above said routine analysis.

\section{ACKNOWLEDGEMENT}

The authors are thankful to the Chairperson, Department of Chemistry, Himachal Pradesh University, Shimla, Himachal Pradesh (171005) for providing facilities. One of the authors, Pushap Raj is thankful to the University Grant Commission for JRF.

\section{AUTHORS CONTRIBUTIONS}

D. K. Sharma and Jasvir Singh: Original idea, design of work. Pushap Raj: Preparation of reagents and solutions and execution of experiments, D. K. Sharma and Pushap Raj: Data interpretation and manuscript writing. All authors read and approved the final manuscript.

\section{CONFLICT OF INTERESTS}

The authors declare that there are no competing interests.

\section{REFERENCES}

1. Sartori ER, Medeiros RA, Rocha-Filho RC, Fatibello-Filho O. Square-wave voltammetric determination of propranolol and atenolol in pharmaceuticals using a boron-doped diamond electrode. Talanta 2010;81:1418-24.

2. Yilmazi B, Arslan S. Development and validation of GC-MS method for determination of metoprolol in human urine. J Chromatogr Sci 2010;48:1-5.

3. Sharma F, Jain H, Kanzariya V, Upadhyay U. Formulation and evaluation of controlled release osmotic tablet of metoprolol succinate. Asian J Pharm Clin Res 2014;7:38-43.

4. Thulluru A, Kumar VS, Kumar P, Roshitha B. Effect of effervescence in combination with superdisintegrants in the formulation of propranolol $\mathrm{HCl}$ oral disintegrating tablets. Asian J Pharm Clin 2017;10:227-34.

5. Er E, Celikkan H, Erk N. A novel electrochemical nano-platform based on graphene/platinum nanoparticles/nafion composites for the electrochemical sensing of MTP. Sens Actuators B 2017;238:779-87.

6. Valderrama P, Poppi RJ. Determination of propranolol enantiomers in plasma and urine by spectrofluorimetry and second-order standard. Anal Chim Acta 2009;651:31-5.

7. Esteve-Romero J, Albiol-Chiva J, Peris-Vicente J. A review on development of analytical methods to determine monitorable drugs in serum and urine by micellar liquid chromatography using direct injection. Anal Chim Acta 2016;926:1-16.

8. Daneshkhah $M$, Hossaini $H$, Malakootian M. Removal of metoprolol from water by sepiolite-supported nanoscale zerovalent iron. J Environ Chem Eng 2017;5:3490-9.

9. Rivera Utrilla J, Sanchez Polo M, Ferro Garcia MA, Prados Joya G, Ocampo Perez R. Pharmaceuticals as emerging contaminants and their removal from water. A review. Chemosphere 2013;93:1268-87.

10. Salem H. Spectrophotometric determination of-adrenergic blocking agents in pharmaceutical formulations. J Pharm Biomed Anal 2002;29:527-38.

11. Amin AS, Ragab GH, Saleh H. Colourimetric determination of bblockers in pharmaceutical formulations. J Pharm Biomed Anal 2002;30:1347-53.

12. Bhandari A, Kumar B, Patel R. Spectrophotometric estimation of propranolol in tablet dosage form. Asian J Chem 2008;20:802-4.
13. Madrakian T, Afkhami A, Mohammadnej M. Simultaneous spectrofluorimetric determination of levodopa and propranolol in urine using feed-forward neural networks assisted by principal component analysis. Talanta 2009;78:1051-5.

14. Walash MI, Belal F, El-Enany NM, El-Maghrabey MH. Synchronous fluorescence spectrofluorimetric method for the simultaneous determination of metoprolol and felodipine in combined pharmaceutical preparation. Chem Cent J 2011;5:1-9.

15. Brunetto MR, Clavijo S, Delgado Y, Orozco W, Gallignani M, Ayala C, et al. Development of a MSFIA sample treatment system as front end of GC-MS for atenolol and propranolol determination in human plasma. Talanta 2015;132:15-22.

16. Yilmaz B, Arslan S, Akba V. Gas chromatography-mass spectrometry method for determination of metoprolol in the patients with hypertension. Talanta 2009;80:346-51.

17. Baranowska I, Adolf W, Magiera S. Enantioselective determination of metoprolol and its metabolites in human urine high-performance liquid chromatography with fluorescence detection (HPLC-FLD) and tandem mass spectrometry (MS/MS). J Chromatogr B: Anal Technol Biomed Life Sci 2015;1004:79-84.

18. Ren Dan Z, Lai Sheng L, Biao Ping C, Gui Zhen N, Hong Fu Z. Enantioseparation and determination of propranolol in human plasma on a new derivatized $\beta$-cyclodextrin-bonded phase by HPLC. Chin J Anal Chem 2014;42:1002-9.

19. Trobec KC, Tronteji J, Springer J, Lainscak M, Kos MK. Liquid chromatography-tandem mass spectrometry method for simultaneous quantification of bisoprolol, ramiprilat, propranolol and midazolam in rat dried blood spots. J Chromatogr B 2014;958:29-35.

20. Barclay VKH, Tyrefors NL, Johansson IM, Pettersson CE. Chiral analysis of metoprolol and two of its metabolites,-hydroxy metoprolol and deaminated metoprolol, in wastewater using liquid chromatography-tandem mass spectrometry. J Chromatogr A 2012;1269:208-17.

21. Partani P, Moshave Y, Gurule S, Khuroo A, Monif T. Simultaneous determination of propranolol and 4-hydroxy propranolol in human plasma by solid phase extraction and liquid chromatography/electrospray tandem mass spectrometry. J Pharm Biomed Anal 2009;50:966-76.

22. Liu H, Ren J, Hao Y, Ding H, He P, Fang Y. Determination of metoprolol tartrate in tablets and human urine using flow injection chemiluminescence method. J Pharm Biomed Anal 2006;42:384-8.

23. Qi Y, Xiu F. Sensitive and rapid chemiluminescence detection of propranolol based on effect of surface charge of gold nanoparticles. J Lumin 2016;171:238-45.

24. Micke GA, Costa ACO, Heller M, Barcellos M, Pioezan M, Caon T, et al. Development of a fast capillary electrophoresis method for the determination of propranolol-total analysis time reduction strategies. J Chromatogr A 2009;1216:7957-61.

25. Chen YY, Yang WP, Zhang ZJ. Determination of metoprolol in rabbit blood using capillary electrophoresis with laser-induced fluorescence detection. Chin Chem Lett 2011;22:350-3.

26. Oliveira GG, Azii DC, Vicentini FC, Sartori ER, Fatibello-Filho O. Voltammetric determination of verapamil and propranolol using a glassy carbon electrode modified with functionalized multiwalled carbon nanotubes within a poly (allylamine hydrochloride) film. J Electroanal Chem 2013;708:73-9.

27. Salamanca Neto CAR, Eisele APP, Resta VG, Scremin J, Sartori ER. Differential pulse voltammetric method for the individual and simultaneous determination of antihypertensive drug metoprolol and its association with hydrochlorothiazide in pharmaceutical dosage forms. Sens Actuators B: Chem 2016;230:630-8.

28. Verma BC, Sood RK, Sharma DK, Sidhu HS, Chauhan S. Improved spectrophotometric method for the determination of thiram residue in grains. Analyst 1984;109:649-50.

29. Kokubo T, Kushitani H, Sakka S, Kitsugi T, Yamamuro T. Solutions able to reproduce in vivo surface-structure changes in bioactive glass-ceramic A-W. J Biomed Mater Res 1990;24:721-34.

30. Miller JD, Randolph AD, Drach GW. Observations upon calcium oxalate crystallization kinetics in simulated urine. J Urol 1977;117:342-5. 
31. Singh CL, Singh A, Kumar S, Kumar M, Sharma PK, Majumdar DK. Development and validation of different ultraviolet spectrophotometric methods for the estimation of besifloxacin in different simulated body fluids. Indian J Pharm Sci 2015;77:399-404.

32. Verma BC, Chauhan S, Sharma N, Sharma U, Sharma DK, Sood A. Analytical applications of the amine-carbon disulphide reaction in acetonitrile. Talanta 1986;33:703-4.

33. Verma BC, Sood RK, Chauhan S, Sood A, Sharma NK, Sharma DK. A new technique for measurement of carbon disulphide evolved in acid hydrolysis method for the analysis of dithiocarbamate fungicides in formulations and residues. Proc Indian Nat Sci Acad 1986;52:1420-7.
34. Sharma DK, Raj P. Simple and rapid spectrophotometric determination of atenolol and esmolol $\beta$-blockers in pharmaceutical formulations and spiked water samples. Int J Pharm Sci Res 2017;8:1000-10.

35. Navarro DA, Strotz CA. Microwave-assisted alkaline modification of red seaweed galactans. Carbohydr Polym 2005;62:187-91.

36. ICH-International Conference on Harmonization. Topic Q2 (R1), Validation of Analytical Procedures: Text and Methodology. International conference on harmonisation of technical requirements for registration of pharmaceuticals for human use. Geneva; 2005. p. 1-13. 